\title{
Minimally invasive search for a missing vibrator
}

Greg J. Marchand, MD, FACS, FACOG, FICS ${ }^{1}$, Ali Azadi, MD², Akarshi Kaue Brar, PhD², Katelyn Sainz, MD 1,3, Sienna Anderson, BS 1 , Stacy Ruther, BS ${ }^{1}$, Kelly Ware, MS ${ }^{1,3,4}$, Sophia Hopewell, BS ${ }^{1}$, Giovanna Brazil, BS ${ }^{1}$, Katerina Meassick, MS ${ }^{3,5}$, Hannah Wolf, BS ${ }^{1}$, Alexa King, BS ${ }^{1}$, Jannelle Vallejo, MS ${ }^{1,3}$, Kaitlynne Cieminski, BS ${ }^{1}$, Anthony Galitsky, MD'

${ }^{1}$ The Marchand Institute for Minimally Invasive Surgery, Mesa, ${ }^{2}$ Star Urogynecology, Peoria, AZ, USA; Department of Medicine, ${ }^{3}$ Washington University of Health and Science, San Pedro, Belize, ${ }^{4}$ International University of Health Sciences, Basseterre, Federation of Saint Kitts and Nevis, ${ }^{5}$ Midwestern University School of Medicine, Glendale, AZ, USA

\section{Objective}

To report a unique surgical procedure that was utilized to locate a missing vibrator in the pelvis of a patient. Emergency room admissions and surgery secondary to the malfunctioning of devices intended for sexual stimulation are extremely common. Emergency room staff of hospitals in the United States usually are skilled in the detection and removal of these devices. Occasionally, surgical intervention is warranted if the device enters a cavity that cannot safely be explored in the emergency room setting. We report a case of a vibrator that was lost during sexual activity. A flat plate X-ray showed it to be in the abdominal cavity. Careful questioning of the patient revealed that the device had an unusually small diameter. Surgical intervention showed that the device ultimately ended up in the bladder without causing traumatic injury.

Methods

We created a narrated video to demonstrate the surgical procedure (Canadian Task Force Classification III).

Results

Laparoscopy and cystoscopy were used to visualize and successfully remove the device. The patient recovered uneventfully.

\section{Conclusion}

Following laparoscopic confirmation of the location of the device, it was removed via cystoscopy. This case demonstrates how background information, such as the size of the missing device in this case, can be critical to providing high quality patient care.

Keywords: Cystoscopy; Laparoscopy; Foreign bodies; Vibrator

In the United States, injuries from the use of sex-related instruments are a very common reason for emergency room visits [1,2]. Insertion of the instrument and its penetration through the vaginal wall regularly result in the object penetrating the abdominal cavity $[3,4]$, leading to possible bowel damage. It is rare for large objects to enter and become trapped in the bladder [5].

A 29-year-old G1 Po Ab1 Caucasian woman visited the emergency room at about 1 A.M. and reported that her vibrator had become lost during sexual activity. The patient said that her partner suddenly started vaginal intercourse after using the vibrator to stimulate the clitoris directly. The patient was uncertain about the location of the vibrator and
Received: 2020.05.01. Revised: 2020.05.25. Accepted: 2020.06.15. Corresponding author: Greg J. Marchand, MD, FACS, FACOG, FICS

The Marchand Institute for Minimally Invasive Surgery, 10238 E Hampton Avenue, Suite 212, Mesa, AZ 85209, USA

E-mail: gm@marchandinstitute.org

https://orcid.org/0000-0003-4724-9148

Articles published in Obstet Gynecol Sci are open-access, distributed under the terms of the Creative Commons Attribution Non-Commercial License (http://creativecommons. org/licenses/by-nc/3.0/) which permits unrestricted non-commercial use, distribution, and reproduction in any medium, provided the original work is properly cited.

Copyright $\odot 2020$ Korean Society of Obstetrics and Gynecology 


\section{Obstetrics \& Gynecology Science}

Vol. 63, No. 5, 2020

felt discomfort for a while. She thought the vibrator was in the vagina as sexual intercourse progressed because she could still feel the vibration. After intercourse, the patient could not find the vibrator in the vagina but still felt the sensation of vibration within the pelvis. When the patient was unable to find the vibrator, she presented to the emergency room. She stated that the vibration lasted about 30 minutes, approximately the battery life of the device. An X-ray of the pelvis showed that the vibrator was approximately at the level of the intrauterine device of the patient within pelvis and in the horizontal position.

Careful questioning of the patient revealed that the vibrator was an unusual type called Vesper ${ }^{\mathrm{TM}}$ (Crave Corp., Bloomington, MN, USA), which has an unusually small diameter of approximately $1.2 \mathrm{~cm}$. The device is approximately 10 $\mathrm{cm}$ long and on a chain to be worn like a necklace, maximizing the ease of use of the vibrator. The chain can be removed to use the vibrator for sexual activity. The patient confirmed that she removed the chain from the device before use.

Repeated vaginal and rectal examinations by the emergency room staff and gynecologists did not show evidence of the device in either the vagina or the rectum, so it was assumed that the device passed through the vaginal wall and entered the abdominal cavity. The patient had a body mass index of 22.5, so it was believed that her weight did not affect the examinations. It was assumed that the colon had not ruptured because of the limited softness found on examination. However, before laparoscopic exploration, the patient agreed to undergo a colostomy and repair of the colon if found necessary. Laparoscopic exploration showed that the device was in the bladder. Its location was also demonstrated by moving a sponge stick placed in the vagina and by gently manipulating the poly bulb. The vibrator was visualized and removed with a cystoscope.

To safely remove the vibrator through the urethra, it was necessary to fill the bladder with about $1 \mathrm{~L}$ of normal saline to change the orientation of the vibrator from horizontal to vertical, resulting in no morbidity from removal. The patient recovered without incident immediately after removal of the foreign body and was discharged from the hospital.

To provide the highest level of care when treating a patient with a foreign body, it is important to understand, as much as possible, the object in question [6-8]. Most gynecologists are familiar with sex-related injuries and associated morbidities. In situations similar to that of our patient, most gyne- cologists generally assume that the vibrator will be too large to fit through the urethra [9-12]. In our case, the vibrator was measured to have an maximum diameter of about 1.2 $\mathrm{cm}$, which is about the same as the diameter of a 36 French catheter. Thus, the device was able to enter the urethra and occupy the bladder without damaging it $[13,14]$.

Another interesting aspect of this case was that the device was assumed to be in the pelvic cavity because it appeared on the X-ray to be approximately at the level of the intrauterine device. Retrospectively, we believe that if a computed tomography scan had been performed or a lateral X-ray taken, the radiologist might have been able to accurately locate the device. Thus, the patient could have been spared the laparoscopy because the device could have been removed with a simple cystoscopy.

\section{Conflict of interest}

No potential conflict of interest relevant to this article was reported.

\section{Ethical approval}

The Institutional Review Board (IRB) committee at the Marchand Institute for Minimally Invasive Surgery reviewed this study and determined that it was exempt from IRB approval.

\section{Video clip}

Video can be found with this article online at https://doi. org/10.5468/ogs.20121.

\section{References}

1. Haft JS, Benjamin HB, Wagner M. Vaginal vibrator lodged in rectum. Br Med J 1976;1:626.

2. McLean I, Roberts SA, White C, Paul S. Female genital injuries resulting from consensual and non-consensual vaginal intercourse. Forensic Sci Int 2011;204:27-33.

3. Jones JS, Rossman L, Hartman M, Alexander CC. Anogenital injuries in adolescents after consensual sexual 


\section{Obstetrics \& Gynecology Science}

Greg J. Marchand, et al. Search for a missing vibrator

intercourse. Acad Emerg Med 2003;10:1378-83.

4. Bowyer L, Dalton ME. Female victims of rape and their genital injuries. Br J Obstet Gynaecol 1997;104:617-20.

5. Zink T, Fargo JD, Baker RB, Buschur C, Fisher BS, Sommers MS. Comparison of methods for identifying anogenital injury after consensual intercourse. J Emerg Med 2010;39:113-8.

6. Slaughter L, Brown CR, Crowley S, Peck R. Patterns of genital injury in female sexual assault victims. Am J Obstet Gynecol 1997;176:609-16.

7. Biggs M, Stermac LE, Divinsky M. Genital injuries following sexual assault of women with and without prior sexual intercourse experience. CMAJ 1998;159:33-7.

8. Poulos CA, Sheridan DJ. Genital injuries in postmenopausal women after sexual assault. J Elder Abuse Negl 2008;20:323-35.

9. Hilden M, Schei B, Sidenius K. Genitoanal injury in adult female victims of sexual assault. Forensic Sci Int 2005;154:200-5.

10. Sommers MS. Defining patterns of genital injury from sexual assault: a review. Trauma Violence Abuse 2007;8:270-80.

11. Demir RH. Effect of improved vaginal manipulator on laparoscopic sacrocolpopexy. J Minim Invasive Gynecol 2013;20:S69.

12. Frioux SM, Blinman T, Christian CW. Vaginal lacerations from consensual intercourse in adolescents. Child Abuse Negl 2011;35:69-73.

13. Anderson S, McClain N, Riviello RJ. Genital findings of women after consensual and nonconsensual intercourse. J Forensic Nurs 2006;2:59-65.

14. Walker $G$. The (in)significance of genital injury in rape and sexual assault. J Forensic Leg Med 2015;34:173-8. 